\title{
Acute Normovolemic Hemodilution
}

National Cancer Institute

\section{Source}

National Cancer Institute. Acute Normovolemic Hemodilution. NCI Thesaurus. Code C116547.

A method of intraoperative blood conservation in which whole blood is drained by gravity into a collection bag where it is mixed with anticoagulants and maintained at room temperature. As the blood is collected, an intravenous fluid is infused to maintain normal blood volume. The collected blood can be transfused to the patient during and/or after surgery as needed. 